\title{
Macroeconomic Consequences of Terrorist Attacks in Pakistan
}

\section{Yuan-lei Liu, San-yu Zhou, Xiao-he Chen}

Institute of Finance and Economics, Shanghai University of Finance and Economics, Shanghai, China

\section{Email address:}

hdyqsm@163.com (Yuan-lei Liu), simplezsy@sina.com (San-yu Zhou), chx825454@mail.shufe.edu.cn (Xiao-he Chen)

\section{To cite this article:}

Yuan-lei Liu, San-yu Zhou, Xiao-he Chen. Macroeconomic Consequences of Terrorist Attacks in Pakistan. Science Innovation. Vol. 5, No. 6, 2017, pp. 349-355. doi: 10.11648/j.si.20170506.13

Received: August 21, 2017; Accepted: October 5, 2017; Published: October 27, 2017

\begin{abstract}
China-Pakistan economic corridor is one of flagship projects in "the Belt and Road Initiatives", it not only will provide energy channels besides the Strait of Malacca but also will greatly shorten the oil transport distance (85\%). However, the frequent tribal conflicts and terrorist attacks in Pakistan will threaten the safety of China-Pakistan economic corridor. Based on the classification of the violence in Pakistan, the paper tries to find the source of the conflicts from the economy and politics. This research finds that: the better political environment and more harmonious race relations can greatly suppress the outbreak of the conflict; Unemployment is positively related to the number of terrorist attacks; Economics plays an important role in all kinds of conflicts. Based on the research, the paper offers some advice to reduce the conflict.
\end{abstract}

Keywords: Negative Binomial Regression, Terrorism, China-Pakistan Economic Corridor

\section{巴基斯坦政治经济环境对安全形势影响的研究}

刘元雷, 周三玉, 陈晓和

上海财经大学, 财经研究所, 上海, 中国

邮箱

hdyqsm@163.com（刘元雷），simplezsy@sina.com（周三玉）, chx825454@mail.shufe.edu.cn（陈晓和）

摘要：中巴经济走廊系“一带一路”倡议的旗舰项目, 它不仅提供除马六甲海峡之外的能源通道而且将极大地缩短石油 运输距离 $(85 \%$ ）。然而, 频繁爆发的部落冲突和恐怖袭击将对中巴经济走廊构成极大的安全隐患。本文在对暴力冲 突分类的基础上, 梳理巴基斯坦境内暴力冲突的类别, 分别在政治、经济环境中寻求事件的成因。研究发现：就整体 而言, 政治环境越好, 种族关系越和谐, 越能抑制冲突的爆发; 失业人数与恐怖袭击次数正相关; 经济因素对所有的 冲突都有显著影响。基于上述分析文章为减少冲突事件的发生提供了参考策略。

关键词：负二项回归, 恐怖主义, 中巴经济走廊 


\section{1. 引言}

\section{1 . 问题提出}

中巴经济走廊是一条连接中国新疆喀什到巴基斯坦 西南港口瓜达尔港的公路、铁路、油气管道及光缆覆盖的 “四位一体”通道, 是“一带一路”倡议的旗舰项目。中巴经 济走廊把中国目前经马六甲海峡的石油运输距离缩短 85\%。然而, 巴基斯坦境内的安全形势并不乐观一—巴基 斯坦与邻国印度和阿富汗存在严重的领土争端, 国家内部 反叛势力经常制造暴力冲突, 恐怖袭击频繁发生。近年来 袭击的目标逐渐转向基础设施建设上, 这对中巴经济走廊 的建设和运营构成潜在威胁。有效地预防和消除这些恐怖 事件将极大地降低中巴经济走廊的运营成本。本文在对暴 力冲突分层的基础上, 分别研究它们与巴基斯坦的政治、 经济环境之间的关系，为治理暴力事件增加有效选项。

\section{2. 文献综述}

影响巴基斯坦国内安全形势的势力中, 国内恐怖主义 组织是最主要的, 影响范围最广、持续时间最长的。经济 因素被认为是暴力恐怖主义产生的重要原因之一。现有研 究成果中涉及的经济因素有GDP、人均GDP、失业、通货 膨胀等, 但是研究并没有取得一致的结论。 Li、Schaub [9] 和Collier、Hoeffler [5]认为人均GDP增长, 表示人民的生 活水平提高, 则会抑制冲突的爆发。反之, 则会为冲突爆 发提供机会。另一方面, GDP的增长有可能会使得冲突爆 发有所增长。Ray [14]、Caruso、Schneider [4]认为, 人均 GDP上升意味着人民收入上升, 国家资本增多, 从而可掠 夺资源也增多。Zahra、Khalid [17]的研究表明人口增长、 物价水平、贫困程度和政策稳定性与巴境内的恐怖活动发 生有关。其中, 收入水平、失业率和贸易开放程度没有长 期的影响。失业率的影响是双向的, 而价格水平是所有影 响因素中影响力最大的, 贫困程度相对影响能力较小。 Aisha、Shehla [1]则认为短期内巴基斯坦的通货膨胀率、 人均GDP、贫困程度的影响十分明显, 而不平等因素、教 育程度和失业率不显著。长期内人均GDP、货膨胀率和贫 困程度依旧显著, 同时教育程度长期内影响着冲突的发 生。Muhammad等[11]分析了经济增长同巴境内恐怖袭击 的相互影响关系: 长期内经济增长对恐怖活动爆发是有影 响的, 而恐怖主义对经济增长有短期影响。Caruso、

Schneider [4]认为高通货膨胀率通过对经济的影响也会影 响冲突的爆发。

政治因素方面，李丽、苏金金[18]针对俾路支地区恐怖 主义的产生原因进行了分析。一是历史上殖民主义的遗留 问题, 在这一地区伊朗、阿富汗和巴基斯坦分属不同的伊 斯兰教派; 二是民族实行的部落制度导致民族利益高于国 家利益，政府难以管控; 三是这一地区的经济落后导致的 贫困; 四是阿富汗难民的大量涌入, 催生了恐怖主义通道 形成, 便于阿富汗塔利班组织的藏匿。张亚冰[22]分析了 极端主义在巴基斯坦产生的主要原因。作者认为极端主义 的出现根源是巴的伊斯兰化进程。

综上所述在当前的研究中, 学者没有考虑到不同国家 的实际情况。因为不同国家经济发展水平、收入状况、社
会情况不一样, 所以造成国家的冲突原因也不一样, 这也 是很多学者得出的结论不一致的原因之一。其次, 目前研 究多注重于经济影响因素研究, 有关政治影响的因素考虑 不多, 且国内研究多以定性分析为主。而政治因素往往是 出现恐怖主义的主要原因, 恐怖主义的出现、发展往往离 不开政治、社会环境的推动, 所以考虑社会因素十分重要。 最后, 目前的研究多采用时间序列的相关模型, 然而由于 因变量是冲突爆发的次数, 是离散型的, 这与模型的假定 条件不相符, 这类因变量使用普松模型较为合适。

\section{3. 巴基斯坦冲突爆发的历史因素}

巴基斯坦的内部动乱是由历史隐患逐渐形成的, 主要 表现为民族矛盾、部落冲突和宗教派别矛盾等。由于英国 没有考虑普图什民族的领地划分，导致阿巴边境的“杜兰 德线”一直从未真正勘探过，形同虚设，双方在边境线的 认定无法得到共识。各种带有极端宗教主义色彩的组织在 这一地区活跃。在巴基斯坦境内的俾路支人和普什图人都 实行部落制管理，民族独立性强且较为善斗。这两支民族 一直在寻求独立, 从政府手中获取更大的权力, 民族从属 感要高于国家荣誉感。但是巴基斯坦政府在这两个地区的 控制力较差。这些原因都导致巴基斯坦境内成立了很多组 织, 增加了不安全的因素。在国境线未被解决的现状下, 阿巴双方政府均需要利用杜兰德线两侧的部落区扶植对 方的敌对势力。这使得活跃于这一地区的各种组织、力量 得到一定的资金、人员支持。当期现状都在阻碍着政府的 凝聚力。与此同时, 这些地区的经济发展落后, 主要依靠 农业和畜牧业, 但因为气候条件不好, 所以这些地区在遭 遇灾害等情况时, 其收入会进一步减少, 贫穷和升高的失 业率会进一步助长反政府武装的扩大。

\section{4. 巴基斯坦境内冲突类型}

巴基斯坦内部的冲突主要有三类。

1 巴基斯坦政府主导的战争与反恐战争（冲突类型I） 是巴基斯坦作为主权国家参与的冲突、战争。一是巴基斯 坦政府与印度政府有关克什米尔地区的领土主权问题。双 方围绕这一地区有多次摩擦。二是与巴基斯坦塔利班、阿 富汗塔利班进行的反恐战争。从爆发的原因上看, 巴基斯 坦的反恐是印巴分治时的产物和美国发动阿富汗战争的 后续事态发展。同时, 在克什米尔地区也有一些极端势力 所组建的慈善组织, 这些势力在巴国内招募成员, 建立联 络办事处等。这类组织中比较有影响力的是圣战者党 (hIzb-ul-Mujahideen) 和虔诚军 (Lashka-e-Taiba)。这 种做法进一步扩大了极端宗教势力在巴基斯坦境内的影 响。目前这类冲突对象有三, 一是巴政府与在领土问题上 偶有摩擦的印度政府, 二是与美军一起打击的潜伏于巴境 内的塔利班组织, 三是巴政府与巴塔、基地组织和ISIS爆 发的冲突战争。

可以看到, 这类冲突战争都与巴政府的政策、统治力 等因素有关, 同巴基斯坦的政治环境有很大关系。这些组 织一般都是以宗教形式开展活动的, 对人民进行洗脑, 把 宗教教义高于政府的“世俗化”管理。要防止人民被宗教势 力洗脑, 从而参与到恐怖主义组织中, 就要有与之对抗的 
“世俗化”力量。政府作为这种“世俗化”统治的一方, 要增 加自身的公信力和凝聚力。一方面是增加政府的立法强 度、构建开放的民主环境。立法越完善, 执行度越高, 在 有法律保障的前提下，宗教的极端“信仰”会有所限制。另 一方面国内的政治环境开放, 允许国内代表不同势力、团 体、民族利益的政党参与, 加强这些团体通过法律、规则 的保护下，合理合法地拥有政治话语权，会弱化宗教极端 势力组织对人民的煽动。巴基斯坦国内民族众多、部落分 布很广，同时还包括阿富汗难民及印度伊斯兰教移民等。 所以政治环境是否开放对巴基斯坦十分重要。此外, 恐怖 主义扩大势力与政府进行对抗是需要人员和资金的。从人 员上来说，人民一般都是风险厌恶型的，参与冲突叛乱的 风险很大, 人们不会主动去参与叛乱。但当经济条件不好 时, 失业率上升, 容易被极端宗教势力洗脑, 从而参加组 织。同时, 经济的落后带来的一系列社会问题, 如教育、 社会保障等问题促使人民去参加宗教势力, 获取精神上的 安尉。从资金来源上说，这些组织一般以走私等非法活动 为主获取大量资金。对于石油资源而言, 由于巴政府还未 完全掌握这一资源, 加之其分布地区又多为西北部部落区 等极端势力的大本营地区。获取石油资源一方面自身可以 获取私利, 占为己用, 另一方面巴国内石油资源供应紧缺, 可以打击巴国内生产所用, 所以是这些组织争夺的重点。 综上所述, 这一类安全问题, 是在与巴基斯坦合作时需要 关注的问题，更是开展与其他中亚、中东欧国家“一带一 路”合作时需要面临的问题。

2 巴基斯坦内部冲突（冲突类型II）。第二类是巴基 斯坦境内发生的在部落、党派之间, 反政府武装组织与政 府之间爆发的冲突。这一类冲突问题也是当前影响巴基斯 坦经济发展及安全形势的主要原因。在与巴政府执政党派 的斗争中, 主要有以下几个组织。第一是乌兹别克斯坦伊 斯兰运动（Islamic Movement of Uzbekistan,简称IMU）和 巴基斯坦塔利班运动（Tehrik-i-Taliban Pakistan,简称 TTP）。这些组织主要活跃在联邦部落直辖区和西北边境 省内的部落区, 流窝发动袭击, 并没有特定的袭击目标, 其政治诉求是实现中亚地区的伊斯兰化, 后者的期望是在 巴基斯坦建立塔利班政权。同时, 还有巴基斯坦虔诚军 （Lashkar-e-Toiba）, 主要活跃在巴控克舍米尔地区, 其 目的是实现克舍米尔地区独立。第二个影响力较大的组织 是俾路支解放军 (BLA,下面简称俾解组织) , 是活跃在 巴基斯坦俾路支省地区的分离主义军, 其中坚力量为三个 部落: 马里 (Marri)、布格提 (Bugti) 和孟格提 (Mangal)。 俾解组织占据着盛产天然气的俾路支省, 并有反华倾向。 其成员组成复杂, 在意识形态上没有统一的思想。

在党派间的斗争中, 持续时间最久, 影响较大的是早 期的印度伊斯兰移民及其后裔与当地部落民族发生的冲 突。在1947年印巴分治后, 从印度移民而来的穆斯林家庭 及其后裔于1984年成立了统一民族运动党（Muttahidah Qaumi Movement, 简称MQM）。这些移民主要集中在巴 基斯坦的旁遮普省和信德省地区, 与当地代表普什图人利 益的人民党 (PPP) 经常发生冲突摩擦。其次, 是不同的 民族、部落间的斗争。比如Turi部落与Mangal之间的斗争。 最后, 是党派内部的斗争。例如TTP是由 13 个部落组成的,
在其一号头目被美无人机杀死后, 内部也因为权力斗争发 生了争斗, 先后表示效忠基地组织和伊斯兰国组织。

从爆发的原因上来看, 这类冲突主要是因为种族、信 仰不同造成的。虽然都是信奉伊斯兰教, 但是一方面伊斯 兰教教派较多, 各个不同派系的教派相互包容度不高, 另 一方面由于民族构成不同，部落不同，导致各方对利益的 分配不满而产生了冲突。一般这些利益与经济和政治地位 有关。经济发展可以带动一系列正面、积极的影响。社会 福利保障提高, 就业机会增多, 人民收入上升, 教育水平 提高都可以使得一些处于游离的人民倾向安稳的生活, 这 类冲突会得到一定程度的缓解。巴政府也一直致力于缓解 不同民族、部落的矛盾，包括经济政策的刺激、和谈等方 式。政府引导对这一类冲突有积极的缓解影响。巴基斯坦 是实行多党制, 不同的党派代表了不同势力, 不同团体利 益。参政的党派越多, 这些党派政治地位提升, 民主化越 高, 使民主化越高, 所以民主化进程对这类冲突影响显著。

3 针对平民的袭击（冲突类型III）。第三类是巴基斯 坦境内的恐怖主义袭击, 这一类冲突是恐怖组织针对平民 及基础设施的袭击。行动目的是对政府、敌对势力党派的 报复行为或者扩大影响制造恐慌。发动这些袭击的组织主 要为俾解组织、巴基斯坦塔利班和强格维军 (LeJ)。这 些组织不追求经济利益, 更多的是为了达到一些政治诉 求, 所以民主化程度会在一定程度上影响这类冲突。从人 员、资金方面的影响而言，由于一些袭击的方式是自杀式 袭击, 需要对人员进“招募培训”。对人员有很大的需求。 所以当失业率增多、经济条件不好越有利于这些组织招募 到人员, 导致袭击频发。目前恐怖主义袭击也越来越倾向 于这类成本低、破坏大、影响广的袭击方式。

巴基斯坦内部冲突是历史原因形成的, 并受到了国外 大国势力相互博弯的影响。而这一地区的矛盾的主要方面 从宏观上, 是阿富汗和巴基斯坦、印度和巴基斯坦的领土 争端矛盾, 由这一问题所引发的冲突及敌对势力的成长是 需要协商的。从巴基斯坦的国内矛盾来看, 这一地区的矛 盾集中于对利益的诉求上, 权力的争夺和经济政策、优惠 政策的诉求上。在目前中巴经济走廊道路选择上, “西线” 主要经过KP省、俾路支省以及巴控克舍米尔地区。这些 结点多处于冲突多发区, 在抗击巴解组织、塔利班等反巴 前线, 极端分子活跃, 安全形势严峻。“东线”则主要途径 旁遮普省和信德省两处经济较发达地区, 理论上安全问题 有一定保障。但“西线”途径的省份领导人则公开表示反 对, 威胁若走“东线”也许同样面临恐怖威胁, 单纯的经济 安抚有可能会陷入恶性出价的循环中。所以, 分析具体导 致巴基斯坦境内冲突爆发的原因、影响因素及机制十分重 要。才能进一步为后续商讨解决路线问题提供安全性依 据, 寻找适合应对巴基斯坦恐怖袭击的对策。

\section{2. 实证分析}

\section{1. 变量与数据}

本文从政治环境、经济环境、种族关系、失业人口、 自然资源等五个方面选取数据。其中, 有关冲突的数据来 自乌普萨拉冲突数据项目 (Uppsala Conflict Data Program, 
简称UCDP）从1990-2015年的观察值。因变量为国家爆发 冲突的次数。鉴于冲突爆发不管是否有人员伤亡，都会带 来一定的经济损失, 所以本文选取的是发生冲突的次数, 不考虑是否有人员伤亡。

政治环境的评估数据来自IPRG数据库，包含三个指 标。一是政府稳定程度。政府稳定程度从政府凝聚力、立 法强度和人民支持三个方面评估。每一项有 1 至 4 四个等 级, 数值越高, 则表示政府的稳定程度越高。二是民主责 任程度, 数据库将政府的民主程度按照几项指标进行划 分，包括执政党的任期期限和时间；是否有其他政治政党、 反对党（非民间团体）；是否有人权的保护；独立的法院、 立法机构等。数值越高, 越接近交替民主（alternating democracy) 类型; 数值越低越接近的独裁 (autarchy) 国 家。三是种族关系, 种族关系的评级为 1 至 4 , 表示由种族、 国籍或语言不同导致的国家紧张程度。数值越高, 表示不 同的种族团体的相互容忍度较高, 则国家的紧张程度越 低。

经济环境的评估数据包括社会经济条件、人均GDP年 增长率和失业人数。其中, 有关社会经济条件的数据来自 IPRG数据库。社会经济条件是指社会中工作上的社会经 济压力可以舒服政府行为、加剧社会不公平。取值范围从 0 到 4,4 代表很低的风险， 0 表示风险很高。人均GDP年增 长率和失业人数来自世界银行数据库。

自然资源的数据包括巴基斯坦境内的两种自然资源 石油和天然气租金占GDP的比重, 数据来自世界银行数据 库。

\section{2. 数据的描述性统计分析}

由图1可以看出三种类型的冲突近年来爆发异常频 繁, 尤其是第一类冲突呈现出“山峰”状。这主要与强权干 预地区事务及巴基斯坦政局不稳密切相关。图1也表明冲 突爆发的频率趋势与社会经济条件、政府稳定程度、民主 程度、种族关系、自然资源租金和失业时间序列曲线呈现 出明显的正相关或负相关。这使得本文有必要使用普松模 型进行实证分析。

\section{历年冲突次数}

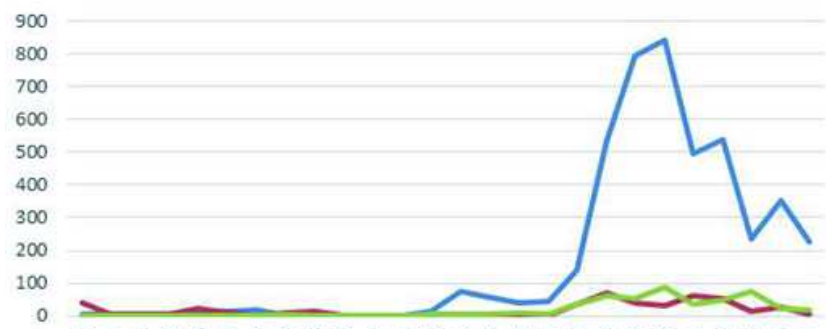

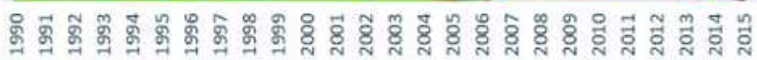

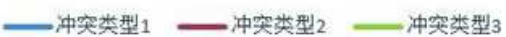

自然资源历年租金变化

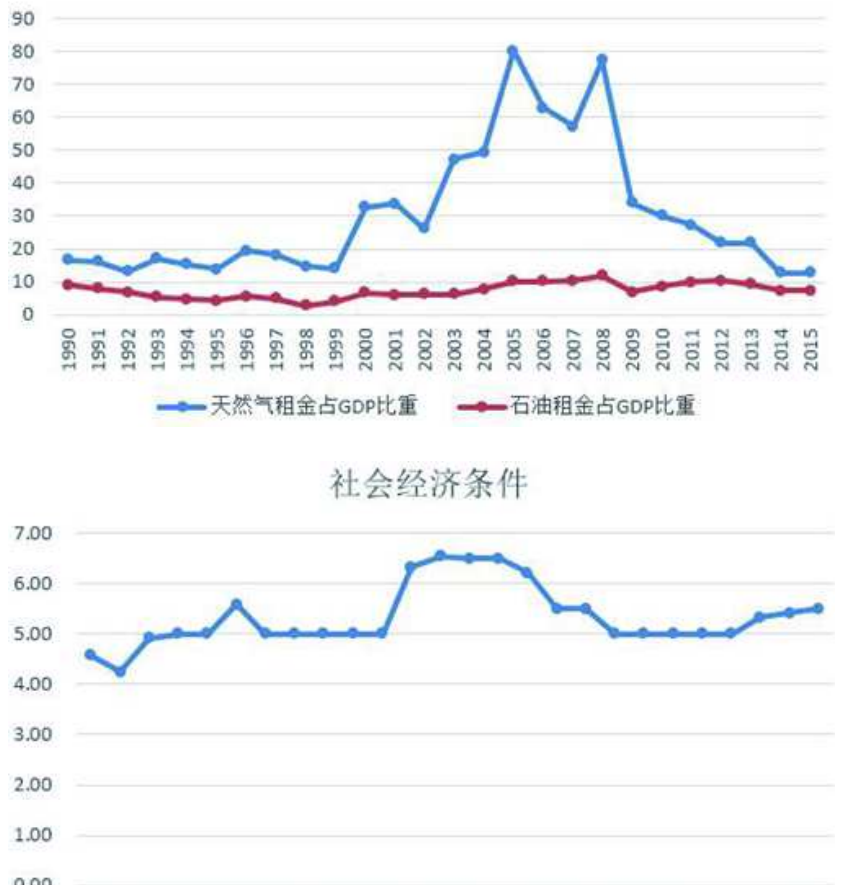

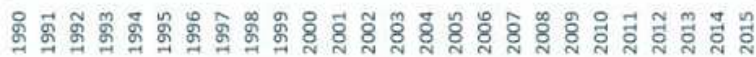
政府稳定程度

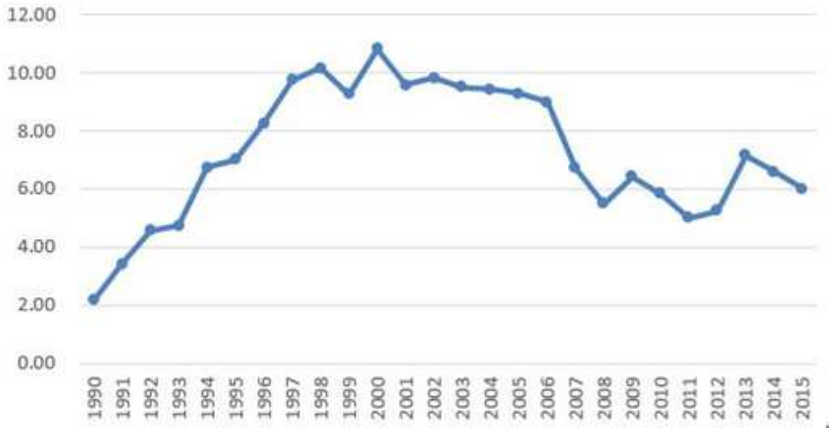

独裁程度

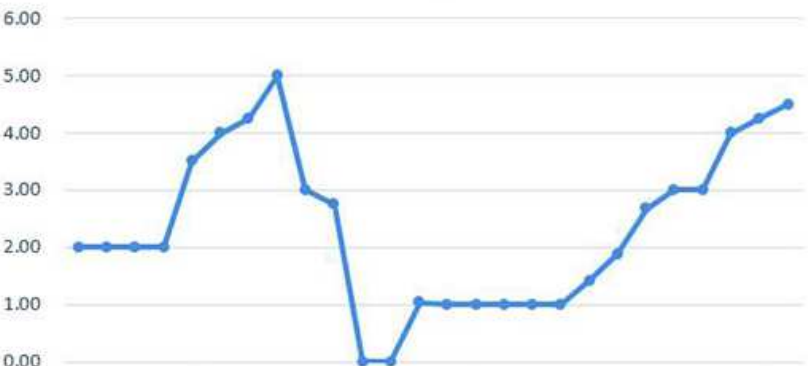

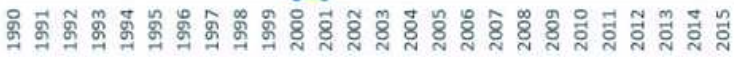




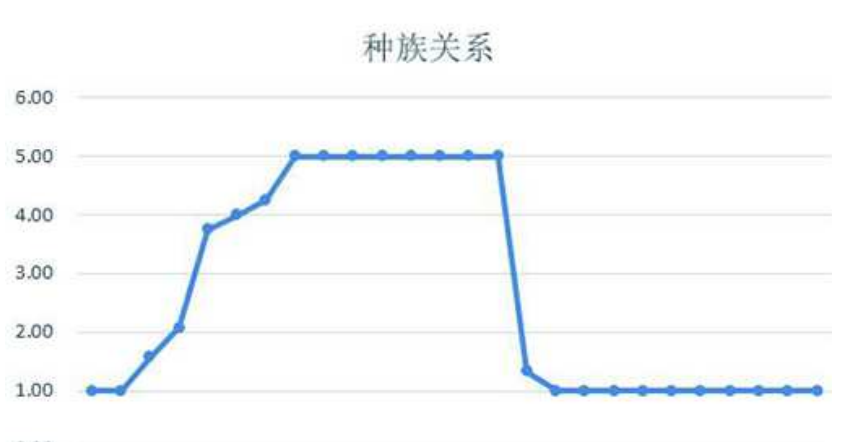

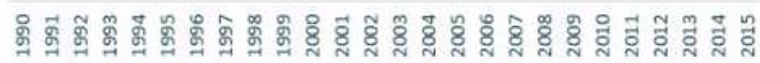

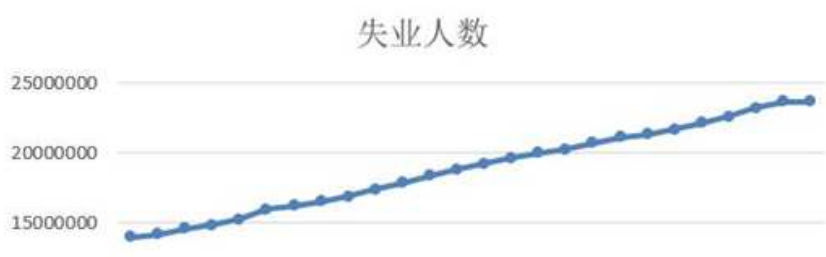

10000000

5000000

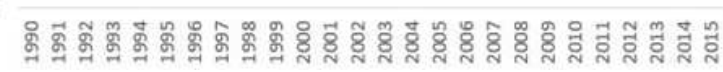

图1 主要变量的变化趋势图。

\section{3. 实证分析}

实证分析的模型是:

$$
\mathrm{T}_{\mathrm{i}}=\alpha+\beta L_{i}+\lambda E_{i}+\gamma X_{i}+\varepsilon_{i}
$$

其中, $\mathrm{Ti}$ 表示在第 $\mathrm{i}$ 年发生的冲突次数, $\alpha$ 是常数项, $\mathrm{Li}$ 是社会、政治影响因素向量, $\mathrm{Ei}$ 是第 $\mathrm{i}$ 年社会经济因素向 量, $\mathrm{Xi}$ 是进行稳定性检验的变量。 $\varepsilon_{i}$ 是随机误差项。

由于因变量是非负整数, 常采用泊松分布。但其期望 与方差要求相等, 若被解释变量的方差明显大于期望, 采 用负二项回归。

1 模型选择。冲突爆发次数的均值和标准差见表 1 。 显然, 均值和标准差不相等, 所以采用负二项回归对冲突 类型回归分析。

表 1 冲突次数的均值和方差。

\begin{tabular}{lll}
\hline 冲突次数 & 平均值 & 标准差 \\
\hline 总次数 & 206 & 296.92 \\
冲突类型I & 185 & 264.2 \\
冲突类型II & 25 & 21.77 \\
冲突类型III & 24 & 26.67 \\
\hline
\end{tabular}

2 回归分析。基于模型选择结果, 本文采用负二项分 布回归模型实证研究冲突类型 (I、II和III) 与政府稳定性、 民主责任、社会经济条件、人均GDP增长率、自然资源和 种族关系之间的关系。在每个冲突类型中的模型 (2) 是 在模型 (1) 的基础上删除不显著的变量进行的回归结果。
表2 冲突类型I回归模型参数估计值。

\begin{tabular}{lll}
\hline & 模型 (1) & 模型 (2) \\
\hline 政府稳定程度 & $-0.79^{* * *}$ & $-0.64^{* * *}$ \\
社会经济条件 & $(-4.48)$ & $(-4.81)$ \\
& 0.190 & $0.639^{* *}$ \\
独裁程度 & $(0.39)$ & $(1.99)$ \\
人均GDP年增长率 & 0.42 & $0.435^{* *}$ \\
& $(1.87)$ & $(1.92)$ \\
天然气租金(占GDP百分比) & -0.22 & $-0.28^{* *}$ \\
& $(-1.44)$ & $(-1.65)$ \\
石油租金 (占GDP百分比) & $(2.91)$ & $0.676^{* * * *}$ \\
& $\left(-2.37^{* * *}\right.$ & $(3.47)$ \\
失业人数 & $13.613^{* * * *}$ & $-3.39^{* * *}$ \\
& $(7.61)$ & $(-2.43)$ \\
种族关系 & 0.306 & $11.85^{* * *}$ \\
\hline
\end{tabular}

*表示 $10 \%$ 水平上显著, $* *$ 表示 $5 \%$ 水平上显著, $* * *$ 表示表示 $1 \%$ 水平上显著

对于第一类冲突, 政府稳定程度系数为负, 是 -0.64 。 即政府稳定程度提高, 冲突爆发的次数会减少。同时, 民 主程度越高, 也会使得这类冲突的爆发次数减少。从经济 方面来说, 人均GDP年增长率上升, 社会经济条件的好转、 失业人数下降时, 都有助于降低冲突爆发。从自然资源的 争夺上来看, 天然气租金占GDP比重越高, 冲突的爆发次 数也越高, 而石油租金与之相反。当天然气租金比重增加 时, 即国内的自然资源获利上升, 一方面表示国家政府有 资金进行战争，另一方面也表示对恐怖主义组织来说，可 掠夺的资源也增多，所以冲突频发。而由于巴境内石油资 源多分布于反恐战争的前沿地区, 当石油租金上升时, 会 改善这一地区的经济状况，在一定程度上改善这一地区的 贫穷。同时, 政府的石油租金上涨意味着恐怖组织的获利 减少，资金来源也变少，会降低冲突的爆发。

表3 冲突类型II回归模型参数估计值。

\begin{tabular}{lll}
\hline & 模型 (1) & 模型 (2) \\
\hline 政府稳定程度 & -0.377 & $-0.357^{* * *}$ \\
& $(-1.32)$ & $(-2.56)$ \\
社会经济条件 & -0.351 & \\
独裁程度 & $(-0.45)$ & \\
& $0.576^{* * *}$ & $0.542^{* * * *}$ \\
人均GDP年增长率 & $(2.95)$ & $(3.00)$ \\
& $-0.688^{* * * *}$ & $-0.715^{* * *}$ \\
天然气租金 (占GDP百分比) & $(-2.76)$ & $(-4.42)$ \\
石油租金 (占GDP百分比) & $0.486^{* * *}$ & $0.310^{* * *}$ \\
& -2.18 & $(2.77)$ \\
失业人数 & $(-1.36)$ & \\
种族关系 & 0.184 & \\
\hline
\end{tabular}

注: *表示 $10 \%$ 水平上显著, $* *$ 表示 $5 \%$ 水平上显著, $* * *$ 表示表示 $1 \%$ 水平 上显著

对于第二类冲突，民主化程度与政府的稳定程度同样 影响着冲突的爆发。因为此类冲突是多为民族、党派的内 部冲突, 所以民主化的影响会更大一些。同时可以看到, 种族关系对冲突的缓解有一定推动作用。种族关系缓和, 政府的安抚缓和措施有用处, 即冲突减少。从经济上说, 社会整体经济状况不是显著的, 因为此类冲突是不同派别 
之间对政治地位、经济利益的争夺引起的。仅关心自身党 派的利益, 而对整体的情况不在意。所以若经济有所提高, 则会有一定安抚。但与整体的就业压力及消费信心带来的 社会压力无关。从自然资源上来看, 天然气租金占GDP比 重显著为正,而石油租金占比不显著。同上一类冲突类似, 当天然气租金上升时, 表示可争夺资源增多, 故冲突频发。 而石油资源由于是多数依靠进口, 还处于开发阶段, 国内 现阶段没有能力完全开发, 不能引起各方的争夺和重视。

表4 冲突类型III回归模型参数估计值。

\begin{tabular}{lll}
\hline & 模型 (1) & 模型 (2) \\
\hline 政府稳定程度 & 0.09 & \\
社会经济条件 & $(0.37)$ & \\
独裁程度 & 0.23 & \\
& $(0.46)$ & \\
人均GDP年增长率 & $0.336^{* *}$ & $0.376^{* * * *}$ \\
& $(1.78)$ & $(2.61)$ \\
天然气租金(占GDP百分比) & $-0.625^{* * *}$ & $-0.57^{* * *}$ \\
石油租金(占GDP百分比) & $(-2.51)$ & $(-4.16)$ \\
& $0.342^{* * *}$ & $0.47^{* * *}$ \\
失业人数 & $(2.20)$ & $(3.29)$ \\
& 0.863 & \\
种族关系 & $(0.79)$ & \\
\hline
\end{tabular}

注: $*$ 表示 $10 \%$ 水平上显著, $* *$ 表示 $5 \%$ 水平上显著, $* * *$ 表示表示 $1 \%$ 水平 上显著

对于第三类冲突，可以看到从政治角度来看，民主化 程度越高, 国内政治环境较好, 袭击平民的事件就会有所 降低。经济上, 人均生活水平提高, 就业情况好转则有利 于降低这些袭击事件, 缓解国内的安全形势。从经济方面 来看, 人均GDP年增长率的提升对整体冲突的降低有益。 尤其是对国家内部的冲突及针对平民的袭击影响很大。同 时, 天然气资源也是引发各类冲突的原因。

总之，不同冲突类型的影响因素是不同的。影响冲突 类型I的因素比较全面，这些方面基本上涉及到了国家。治 理的主要方面。冲突类型II除了与政府稳定性相关外, 主要 侧重于经济因素。冲突类型III与国家的民主化程度相关: 民主化程度越高，国内政治环境较好，袭击平民的事件就 会有所降低。此外, 失业人数对袭击次数有着显著影响, 经济因素仍然扮演着重要角色。可以看出, 经济因素是影 响所有冲突（包括冲突类型I、II和III）发生的共同因素。

\section{3. 结论}

目前关于巴基斯坦冲突的研究的主要结论集中于描 述不同派系目标和利益诉求与恐怖袭击或冲突之间的关 系。不同于已有的研究，本文在理性分析的基础上，从已 发生的冲突和恐怖袭击出发, 通过计量分析, 找出冲突事 件的动因。本文研究表明, 除政府本身的稳定程度和民主 化程度外, 失业、资源掠夺和经济因素是冲突事件的诱因。 因此, 通过加速经济发展减少失业水平是减少冲突事件的 有力措施。
政治环境方面，巴基斯坦的政治环境复杂，各个党派 组织势力交错。在进行投资时，与巴基斯坦政府建立良好 的关系和沟通机制十分必要。同时应时刻关注巴基斯坦国 内的政治形势、种族关系的紧张程度，避开短时间内冲突 爆发集中的部落区域。

经济发展方面, 经济发展与冲突的爆发十分紧密。巴 基斯坦政府的反恐战争需要大量资金的支持。提升经济水 平, 降低失业率对缓解民族矛盾也十分重要。从建立中巴 经济走廊的角度来看, 可以在建设时适当雇佣当地不同民 族的人，包括普什图人、俾路支人等，兼顾这些地区的民 族情绪, 真正提高带动这一地区的经济发展, 避免涓滴效 应而导致贫富差距。

自然资源方面, 巴基斯坦石油资源的探明储量较少。 一方面是巴国内的勘探能力有限, 石油资源储量丰富的地 区集中于部落聚集区, 安全形势很差, 难以推进石油勘探 计划。另一方面是开采、炼油能力效率不高。当前巴政府 拟采取一些优惠措施，鼓励企业参与石油的开发中。这些 政策包括输油管线的建设、勘探钻井机械设备的免税政 策、石油天然气的成品销售及缴税优惠等。我国的有能力 的民营企业也可以参与其中，或提供技术支持，推动巴基 斯坦政府的石油开发, 打通石油通路。

\section{参考文献}

[1] Aisha Ismail, Shehla Amjad, Determinants of terrorism in Pakistan: An empirical investigation[J]. Economic Modeling, 2014, 37,320-331.

[2] Brandt, P. T, Sandler, T. Hostage taking: Understanding terrorism event dynamics [J]. Journal of Policy Modeling, 2009, 31(5),758-778.

[3] Bravo, A. B. S., Dias, C. M. An empirical analysis of terrorism: deprivation, Islamism and geopolitical factors $[\mathrm{J}]$. Def. Peace Econ. 2006, 17 (4), 329-341.

[4] Caruso, R Schneider, F. The socio-economic determinants of terrorism and political violence in Western Europe (1994-2007) [J]. Eur. J. Polit. Econ. 2010, 27, 37-49.

[5] Collier P, Hoeffler A. Greed and Grievance in civil War [J]. Oxford Economic Papers,2004 volume 56(4).

[6] Dreher, A., Fischer, J. Government decentralization as a disincentive for transnational terror? An empirical analysis [J]. Int. Econ. Rev. 2010, 51, 981-1002.

[7] Fearon, J. D Laitin, D. D. Ethnicity, insurgency and civil war [J]. Am. Polit. Sci. Rev, 2003, 97(1).

[8] Faiz Ur Rehman, Paolo Vanin, Terrorism risk and democratic preferences in Pakistan [J]. Journal of Development Economics, 2017(124), 95-106.

[9] Li, Q. Schaub, D. Economic globalization and transnational terrorism: a pooled time-series analysis [J]. Conflict Resolute. 2004, 48(2),230-258. 
[10] Mario Arturo Ruiz Estrada, Donghyun Park, Jung Suk Kim, Alam Khan. The Economic impact of terrorism: A new model and its application to Pakistan [J]. Journal of Policy Modeling, 2015(37), 1065-1080.

[11] Muhammad Shahbazm Muhammad Shahbaz Shabbir, Muhammad Nasir Malik, Mark Edward Wolters, An analysis of a causal relationship between economic growth and terrorism in Pakistan [J]. Economic Modeling, 2013, 35, 21-29.

[12] Muller, E. N., Seligson, M. A. Inequality and insurgency. J. Conflict Resolute. 1990, 34 (4), 425-452.

[13] Oyefusi, A. Oil, youths, and civil unrest in Nigeria's delta [J]. Conflict Management. Peace Sci. 2010,27(4), 326-346.

[14] Ray, D. Uneven growth: a framework for research in development economics [J]. J. Econ. Perspect, 2010, 24, 45-60.

[15] Sandler, T Enders. W. Economic consequences of terrorism in developed and developing countries: An overview [J]. European Journal of Political Economy, 2004, 20(2), 301-316.
[16] Sayre, E. Labor market conditions, political events, and Palestinian suicide bombings [J]. Peace Econ. Peace Sci. Public Policy, 2009, 15 (1).

[17] Zahra Malik, Khalid Zaman. Macroeconomic consequences of terrorism in Pakistan [J]. Journal of Policy Modeling, 2013, 35, 1103-1123.

[18］李丽、苏金金. 巴基斯坦的恐怖主义及其对 “一带一路” 战略 的影响 $[\mathrm{J}]$. 西华师范大学学报 (哲学社会科学版), 2015(6):61-67。

[19] 孙龙、尚喆超、胡海清. Poisson回归模型和负二项回归模型 在林火预测领域的应用 [J]. 林业科学. 2012(5).126-129。

[20］曾向红. “一带一路” 的地缘政治想象与地区合作 $[\mathrm{J}]$. 世界 经济与政治，2016(1):46-71+157-158。

[21] 曾向红、陈亚州. 恐怖主义的组织结构: 类型辨析及其影响 [J]. 世界经济与政治, 2016(8):80-103+459。

[22] 张亚冰. 巴基斯坦极端主义的根源、特点及政府 “去极端 化”策略研究 $[J]$. 南亚研究, 2016(1):86-97+156。 